\title{
Influence of spindle material and surface texture on trash content for picking of cotton under variable conditions
}

\section{Veerangouda and D. Asokan}

See end of the Paper for authors' affiliation Author for Correspondence :

M. Veerangouda Department of Farm Machinery and Power Engineering, College of Agricultural Engineering (UAS), Raichur (Karnatak) India Email : m.veerangouda@ rediffmail.com

Received : 12.11.2018; Revised : 18.02.2019; Accepted : 08.03.2019

ABSTRACT : Manual picking of cotton is commonly done in India and it is not only tedious and labour consuming but also costlier than other agricultural operations. Machine picking is, therefore, considered to be viable in minimizing the drudgery involved in hand picking and reducing the cost of cotton picking. The present investigation was undertaken to study the mechanism of picking cotton by the rotating spindles. The spindles were fabricated with the materials selected for the study and they were evaluated for their performance in picking cotton from bolls under laboratory conditions. The spindles were evaluated with the help of the test rig developed for the purpose and the different parameters were recorded. The trash content in the picked cotton ranged from 0 to 74.96 per cent for the selected varieties. The trash content was observed to be minimum with hylum spindle for all the varieties. The trash content was minimum upto the speed of $2000 \mathrm{rpm}$ and increased greatly with the increase in speed of rotation of $2500 \mathrm{rpm}$ and higher speeds. The trash content was minimum at higher level of moisture. The surface texture of the spindles did not show any particular trend of increase or decrease of trash content. The laboratory trials of the spindles revealed that, the hylum spindle of tapered shape with grooves and knurl gave better performance as trash content in the picked cotton was minimum. The speed of rotation within the range of 1000 to $2500 \mathrm{rpm}$ was found to be better in which the trash content was minimum.

- KEY WORDS : Cotton picking, Picking spindles, Trash content, Spindle material

- HOW TO CITE THIS PAPER : Veerangouda, M. and Asokan, D. (2019). Influence of spindle material and surface texture on trash content for picking of cotton under variable conditions . Internat. J. Agric. Engg., 12(1) : 101-106, DOI: 10.15740/HAS/IJAE/12.1/101-106. Copyright@2019: Hind Agri-Horticultural Society. 